\title{
Application of Rough Set Theory and Causality Diagram in Transformer Troubleshooting of Distribution Network
}

\author{
Xuegeng Chen ${ }^{\mathrm{a}}$, Huibin Sui ${ }^{\mathrm{b}}$ \\ School of Electrical Engineering, Shan Dong University, Ji Nan 250000, China \\ a2509249933@qq.com, bsuihuibin@sdu.edu.cn
}

Keywords: Rough set theory, Causal Network, Distribution transformer, Fault- diagnosis.

\begin{abstract}
As the hub equipment in the distribution network, the transformer fault is difficult to diagnose because of its complexity and diversity. The reasons causing these failures are very complex and unobvious which make the transformer fault diagnosis and analysis very difficult. If the state of the transformer can be timely determined, pre-detection of hidden dangers, and excluded quickly, the accidents and maintenance costs will be greatly reduced. So the fault diagnosis of the transformer has a very practical value and significance. In this paper, the method which combines the Rough set theory with Causal Network is proposed to find out the faults in the transformer by diagnosing the oil. A streamlined decision table is formed, which can help diagnosing faults accurately and rapidly. Compared with the conventional IEC triple ratio method, the proposed method has higher fault tolerance and diagnosis precision.
\end{abstract}

\section{Introduction of Rough set theory}

Rough set theory is a mathematical tool characterizing by incompleteness and uncertainty, which can effectively analyze and deal with incomplete information and discover hidden knowledge and reveal potential laws ${ }^{[1,2]}$. The main idea of Rough set theory is to describe the inaccurate or uncertain knowledge with known knowledge bases ${ }^{[3]}$.

In intelligent data analysis, the knowledge in the original decision table information system is not equally important, and even some of the conditional attributes are redundant. The attribute reduction of decision table is to maintain the condition attribute relative to the decision attribute group ability of the same conditions, and delete the unnecessary or unimportant attributes.

\section{Introduction of Causal Network}

Causality Network is based on the traditional reliable network and fault tree analysis technology, it inherits the advantages of partially overcoming the lack of reliability network ${ }^{[4]}$. This method can be used in fault diagnosis of complex industrial systems ${ }^{[5]}$. It expresses the causal relationship through the form of directed graphs containing the joint probability distribution of random variable sets. It is a kind of information frame that combines causal knowledge and probability knowledge ${ }^{[6]}$.

The composition of the causal diagram is usually divided into three steps ${ }^{[7]}$ :

(1) Determine the variables and explanations of the network's model;

(2) Establish a representative of the independent assertion for the directional acyclic graph. From the probability formula, it as follows,

$\mathrm{P}(\mathrm{X})=\prod_{\mathrm{i}=1}^{\mathrm{n}} \mathrm{P}\left(\mathrm{X}_{\mathrm{i}} \mid \mathrm{x}_{1}, \mathrm{x}_{2}, \ldots, \mathrm{x}_{\mathrm{i}-1}\right)$

Determine $Y_{i}$ as the father node of $X_{i}$.so we can get:

$\mathrm{P}\left(\mathrm{X}_{1}, \mathrm{X}_{2}, \ldots, \mathrm{X}_{\mathrm{n}}\right)=\prod_{\mathrm{i}} \mathrm{P}\left(\mathrm{X}_{\mathrm{i}} \mid \mathrm{Y}_{\mathrm{i}}\right)$

(3) Assign the local probability distribution $\left(X_{i} \mid Y_{i}\right)$

First, the Rough set theory is used to reduce the attribute information and reduce the value of the fault information in order to obtain the minimum diagnostic rules. And then a causal network is created to diagnose the faults efficiently and rapidly. According to reference [9], the collection of signs (such as Table 1) and the fault set (such as Table 2) and the connection set (see Table 3) are shown as follows ${ }^{[8]}$. 
Table 1.The sign of fault

\begin{tabular}{|c|c|}
\hline Sign's number & Sign's type \\
\hline$S_{1}$ & Core ground current \\
\hline$S_{2}$ & Three ratio encoding is overheating fault characteristics \\
\hline$S_{3}$ & Winding DC resistance three-phase imbalance \\
\hline$S_{4}$ & Contain water in the oil of the transformer \\
\hline$S_{5}$ & Three-ratio coding is a discharge fault feature \\
\hline$S_{6}$ & The winding ratio is worse \\
\hline$S_{7}$ & Partial Discharge \\
\hline$S_{8}$ & $\varnothing(\mathrm{CO}) / \varnothing\left(\mathrm{CO}_{2}\right)$ \\
\hline$S_{9}$ & The absorption ratio of the windings or the polarization index \\
\hline
\end{tabular}

Table 2.The collection of fault

\begin{tabular}{|c|c|c|}
\hline $\begin{array}{c}\text { Fault's } \\
\text { number }\end{array}$ & Fault's type & $\begin{array}{c}\text { Priori probability } \\
\mathrm{P} / \%\end{array}$ \\
\hline $\mathrm{F}_{1}$ & Core multi-point grounding and local short circuit & 22.17 \\
\hline $\mathrm{F}_{2}$ & Insulation aging & 5.27 \\
\hline $\mathrm{F}_{3}$ & Magnetic flux leakage or magnetic shielding discharge \\
overheating & 6.29 \\
\hline $\mathrm{F}_{4}$ & Turn insulation damage and turn-to-turn short circuit & 6.12 \\
\hline $\mathrm{F}_{5}$ & Insulation damp & 5.06 \\
\hline $\mathrm{F}_{6}$ & Tap changer and lead fault & 13.17 \\
\hline $\mathrm{F}_{7}$ & Suspension discharge & 7.98 \\
\hline $\mathrm{F}_{8}$ & Fence discharge & 14.21 \\
\hline $\mathrm{F}_{9}$ & Winding deformation and turn - to - turn short circuit & 12.02 \\
\hline $\mathrm{F}_{10}$ & Oil discharge & 7.17 \\
\hline
\end{tabular}

Table 3. The collection of set

\begin{tabular}{|c|c|c|c|c|c|c|c|c|c|}
\hline Fault' number & $\mathrm{S}_{1}$ & $\mathrm{~S}_{2}$ & $\mathrm{~S}_{3}$ & $\mathrm{~S}_{4}$ & $\mathrm{~S}_{5}$ & $\mathrm{~S}_{6}$ & $\mathrm{~S}_{7}$ & $\mathrm{~S}_{8}$ & $\mathrm{~S}_{9}$ \\
\hline $\mathrm{F}_{1}$ & 0.90 & 0.818 & - & - & 0.189 & - & 0.30 & - & - \\
\hline $\mathrm{F}_{2}$ & - & 0.219 & - & 0.267 & - & - & - & 0.816 & - \\
\hline $\mathrm{F}_{3}$ & - & 0.713 & - & - & 0.289 & - & 0.35 & - & - \\
\hline $\mathrm{F}_{4}$ & - & - & - & - & 0.515 & 0.80 & 0.90 & 0.681 & - \\
\hline $\mathrm{F}_{5}$ & - & - & - & 0.718 & - & - & - & - & 0.75 \\
\hline $\mathrm{F}_{6}$ & - & 0.674 & 0.87 & - & 0.231 & - & - & - & - \\
\hline $\mathrm{F}_{7}$ & - & - & - & - & 0.863 & - & 0.90 & - & - \\
\hline $\mathrm{F}_{8}$ & - & - & - & 0.416 & 0.879 & - & 0.90 & 0.759 & - \\
\hline $\mathrm{F}_{9}$ & - & 0.149 & - & - & 0.681 & 0.80 & 0.75 & 0.721 & - \\
\hline $\mathrm{F}_{10}$ & - & 0.20 & - & 0.60 & 0.70 & - & 0.90 & - & - \\
\hline
\end{tabular}

The connection in the table 3 can be understood as: On the premise of fault $F_{i}$ occurred, the probability of fault $F_{i}$ lead to the result $S_{1}$, marked as $P\left(F_{i} \mid S_{i}\right) . R_{i j}$ expresses the causality ${ }^{[9]}$.

The data in Table 3 are continuous values, according to the Rough set theory, it is needed to discrete the data. The rule is used in the proposed method, if $R_{i j} \geq 0.5$, it means 2 , if $0<R_{i j}<0.5$, it means 1 , if $\mathrm{R}_{\mathrm{ij}}=0$, it means 0 . These numbers, 1,2 and 0 , represent the probability of causing such a symptom is large, small or none. After discerning these data, the fault diagnosis decision table is formed as Table 4. 
Table 4. The fault diagnosis decision table

\begin{tabular}{|c|c|c|c|c|c|c|c|c|c|}
\hline Fault number & $\mathrm{S}_{1}$ & $\mathrm{~S}_{2}$ & $\mathrm{~S}_{3}$ & $\mathrm{~S}_{4}$ & $\mathrm{~S}_{5}$ & $\mathrm{~S}_{6}$ & $\mathrm{~S}_{7}$ & $\mathrm{~S}_{8}$ & $\mathrm{~S}_{9}$ \\
\hline $\mathrm{F}_{1}$ & 2 & 2 & 0 & 0 & 1 & 0 & 1 & 0 & 0 \\
\hline $\mathrm{F}_{2}$ & 0 & 1 & 0 & 1 & 0 & 0 & 0 & 2 & 0 \\
\hline $\mathrm{F}_{3}$ & 0 & 2 & 0 & 0 & 1 & 0 & 1 & 0 & 0 \\
\hline $\mathrm{F}_{4}$ & 0 & 0 & 0 & 0 & 2 & 2 & 2 & 2 & 0 \\
\hline $\mathrm{F}_{5}$ & 0 & 2 & 2 & 0 & 1 & 0 & 0 & 0 & 0 \\
\hline $\mathrm{F}_{6}$ & 0 & 0 & 0 & 0 & 2 & 0 & 2 & 0 & 0 \\
\hline $\mathrm{F}_{7}$ & 0 & 0 & 0 & 1 & 2 & 0 & 2 & 2 & 0 \\
\hline $\mathrm{F}_{8}$ & 0 & 1 & 0 & 0 & 2 & 2 & 2 & 2 & 0 \\
\hline $\mathrm{F}_{9}$ & 0 & 1 & 0 & 2 & 2 & 0 & 2 & 0 & 0 \\
\hline $\mathrm{F}_{10}$ & & 0 & 0 & 2 & 0 & 0 & 0 & 0 & 2 \\
\hline
\end{tabular}

Reducing the decision table, then obtain the minimum attribute sets: $\left\{\mathrm{S}_{1}, \mathrm{~S}_{2}, \mathrm{~S}_{3}, \mathrm{~S}_{4}, \mathrm{~S}_{6}\right\}$, $\left\{\mathrm{S}_{1}, \mathrm{~S}_{2}, \mathrm{~S}_{3}, \mathrm{~S}_{4}, \mathrm{~S}_{8}\right\},\left\{\mathrm{S}_{1}, \mathrm{~S}_{2}, \mathrm{~S}_{4}, \mathrm{~S}_{6}, \mathrm{~S}_{7}\right\},\left\{\mathrm{S}_{1}, \mathrm{~S}_{2}, \mathrm{~S}_{4}, \mathrm{~S}_{7}, \mathrm{~S}_{8}\right\}$. There is a conclusion attribute corresponding to the condition attribute all 0 in both $\left\{S_{1}, S_{2}, S_{3}, S_{4}, S_{6}\right\}$ and $\left\{S_{1}, S_{2}, S_{3}, S_{4}, S_{8}\right\}$, so remove them. Choose $\left\{\mathrm{S}_{1}, \mathrm{~S}_{2}, \mathrm{~S}_{4}, \mathrm{~S}_{7}, \mathrm{~S}_{8}\right\}$ as Minimal Fault Diagnosis Decision Table and show them in Table 5 , because it is easier to get.

Table 5. The Minimal Fault Diagnosis Decision table

\begin{tabular}{|c|c|c|c|c|c|}
\hline Fault number & $\mathrm{S}_{1}$ & $\mathrm{~S}_{2}$ & $\mathrm{~S}_{4}$ & $\mathrm{~S}_{7}$ & $\mathrm{~S}_{8}$ \\
\hline $\mathrm{F}_{1}$ & 2 & 2 & 0 & 1 & 0 \\
\hline $\mathrm{F}_{2}$ & 0 & 1 & 1 & 0 & 2 \\
\hline $\mathrm{F}_{3}$ & 0 & 2 & 0 & 1 & 0 \\
\hline $\mathrm{F}_{4}$ & 0 & 0 & 0 & 2 & 2 \\
\hline $\mathrm{F}_{5}$ & 0 & 0 & 2 & 0 & 0 \\
\hline $\mathrm{F}_{6}$ & 0 & 2 & 0 & 0 & 0 \\
\hline $\mathrm{F}_{7}$ & 0 & 0 & 0 & 2 & 0 \\
\hline $\mathrm{F}_{8}$ & 0 & 0 & 1 & 2 & 2 \\
\hline $\mathrm{F}_{9}$ & 0 & 1 & 0 & 2 & 2 \\
\hline $\mathrm{F}_{10}$ & 0 & 1 & 2 & 2 & 0 \\
\hline
\end{tabular}

\section{The description of Causal Network}

Using the Causal Network to solve the problems of fault diagnosis, in fact, is to use some signs of faults and calculate the probability of faults quickly, so the causes with the most likely to occur can be determined . Define the following things before calculating ${ }^{[10]}$ :

1) It is known that the existence of the sign set $\mathrm{M}^{+}$, that means all the signs in $\mathrm{M}^{+}$exist, in addition to other signs do not exist;

2) It is known that there is no sign setM ${ }^{-}$, that means all the signs in $\mathrm{M}^{-}$do not exist. In this paper $\mathrm{M}=\left\{\mathrm{S}_{1}, \mathrm{~S}_{2}, \mathrm{~S}_{4}, \mathrm{~S}_{7}, \mathrm{~S}_{8}\right\}, \mathrm{M}=\mathrm{M}^{+}+\mathrm{M}^{-}$.

In the transformer fault diagnosis, a fault must be found to facilitate the maintenance, so the cause with the largest probability by the fault symptoms should be calculated. It is defined as $\max \left\{\mathrm{P}\left(\mathrm{F}_{\mathrm{i}} \mid\right.\right.$ $\left.\mathrm{M}^{+} \cap \mathrm{M}^{-}\right)$\}.Diagnostic steps are as follows:

1) Based on the current fault information, the cause and effect diagram are applied to calculate the occurrence of a layer with its symptoms.

2) Select the sign that has not been done but occurred and has the highest probability, then analyzes the parent node.

3) Select the parent node that has not been carried out and have the highest probability, then use the Causal Network to calculate the conditional probability of the symptom which based on the conditional probability and the prior probability.

4) Repeat steps (2) to (3), according the size of the final probability to determine the cause of the failure and maintenance of the transformer. 


\section{Case Analysis}

In a test, the transformer chromatographic results are shown in Table 6. The intimate ground current measurement value is $0.1 \mathrm{~A}$, and transformer oil in the water content and partial discharge are normal.

Table 6. A transformer of each gas component records (unit: $\mu \mathrm{L} / \mathrm{L}$ )

\begin{tabular}{|c|c|c|c|c|c|c|}
\hline $\mathrm{H}_{2}$ & $\mathrm{CH}_{4}$ & $\mathrm{C}_{2} \mathrm{H}_{6}$ & $\mathrm{C}_{2} \mathrm{H}_{4}$ & $\mathrm{C}_{2} \mathrm{H}_{2}$ & $\mathrm{CO}$ & $\mathrm{CO}_{2}$ \\
\hline 300 & 290 & 67 & 500 & 3 & 440 & 5100 \\
\hline
\end{tabular}

The characteristic gas ratios are measured as follows:

$\mathrm{C}_{2} \mathrm{H}_{2} / \mathrm{C}_{2} \mathrm{H}_{4}=0.006, \mathrm{CH}_{4} / \mathrm{H}_{2}=0.967, \mathrm{C}_{2} \mathrm{H}_{4} / \mathrm{C}_{2} \mathrm{H}_{6}=7.46, \mathrm{CO} / \mathrm{CO}_{2}=0.086$.

The third ratio is encoded as 002 . Look up the table, it belongs to signs of high temperature. From the Table 1, it is fault $S_{2}$, so $\mathrm{M}^{+}=\left\{\mathrm{S}_{2}\right\}, \mathrm{M}^{-}=\left\{\mathrm{S}_{1}, \mathrm{~S}_{4}, \mathrm{~S}_{7}, \mathrm{~S}_{8}\right\}$.

According to the computational process mentioned above, $\mathrm{P}\left(\mathrm{F}_{\mathrm{i}} \mid \mathrm{M}^{+} \cap \mathrm{M}^{-}\right)$are calculated and the results are shown in Table 7.

Table 7. The probability of failure $\mathrm{P}\left(\mathrm{F}_{\mathrm{i}} \mid \mathrm{M}^{+} \cap \mathrm{M}^{-}\right)$

\begin{tabular}{|c|c|c|c|c|c|c|c|c|c|c|}
\hline & \multicolumn{10}{|c|}{ The reason of failure } \\
\cline { 2 - 11 } & $\mathrm{F}_{1}$ & $\mathrm{~F}_{2}$ & $\mathrm{~F}_{3}$ & $\mathrm{~F}_{4}$ & $\mathrm{~F}_{5}$ & $\mathrm{~F}_{6}$ & $\mathrm{~F}_{7}$ & $\mathrm{~F}_{8}$ & $\mathrm{~F}_{9}$ & $\mathrm{~F}_{10}$ \\
\hline $\mathrm{P}$ & 0.018 & 0.0021 & 0.0384 & 0 & 0 & 0.0896 & 0 & 0 & 0.0017 & 0.0009 \\
\hline
\end{tabular}

As can be seen from Table 7, the probability of the fault label $F_{6}$ is the largest, according to Table 2 , the cause is the tap-changer fault. The actual failure analysis result is that medium voltage switch B small burns, which is consist with the result in this paper.

\section{Conclusion}

Transformer, as a hub of the power grid, its fault diagnosis is of great significance. This paper focuses on the analysis of the internal fault diagnosis of the transformer. The Rough set theory is used to filter the fault information, the redundant information is eliminated under the premise without affecting the diagnosis. Then the Causal Network is applied to simplify the fault network's structure and calculate the reasonable cause to the failure. And the validity and accuracy of the proposed method are demonstrated by the final example.

\section{References}

[1] Qiuye, Li Ming. Rough Set Theory and Its Application in Electric Power Industry [M]. Bei Jing: Machinery Industry Press. 2009.

[2] Huang Wentao, Zhao Xuezeng, et al. Extraction method of decision rules for fault diagnosis based onrough set theory [J]. Proceedings of the CSEE, 2003, 23 (11): 150-154.

[3] Qian Zheng, Yang Li, Zhang Guanjun, et al. Fault diagnosis method of power transformer based on fuzzy reasoning and covering theory $[\mathrm{J}]$. Advanced Technology of Electrical Engineering and Energy, 1999, 18 (3): 36-39.

[4] Zhang Wenxiu. Rough Set Theory and Method [M]. Bei Jing: Science Press, 2001.

[5] Lin Shimin, Lu YuChan, Tian Fengzhan. Construction and applications in data mining of Bayesian Networks [J]. Journal of Tsinghua University (Sci\&Tech), 2001, 41 (1): 49-52.

[6] Liu Zhiqiang. Causation, Bayesian network and cognitive maps [J]. Acta Automatica Sinica, 2001, 27 (4): 552-566.

[7] Wang Nan, Lv Fangcheng, Liu Yunpeng, et al. Synthetic fault diagnosis of oil-immersed power transformer based on rough set theory and fuzzy Petri nets [J]. Proceedings of the CSEE, 2003, 23(12): 128-132.

[8] Zen Huanglin. Rough Set Theory and Its Application [M]. Chong Qing: Chongqing University Press, 1998.

[9] Dong Qiguo. Fault and Diagnosis of Power Transformer [M]. Bei Jing: China Electric Power Press, 2001.

[10]Wang Ya, Miao Duoqian, Zhou Yujian. A Summary of Rough Set Theory and Application [J]. Pattern Recognition and Artificial Intelligence, 1996, 9(4): 337-344. 